\title{
SENTENÇAS CITRA PETITA E A IMPOSIÇÃO DA FUNDAMENTAÇÃO NO NOVO CÓDIGO DE PROCESSO CIVIL
}

\author{
CITRA PETITE STATEMENTS AND THE IMPOSITION OF THE \\ FOUNDATION IN THE NEW CIVIL PROCESS CODE
}

\section{Natália Oster Piccoli ${ }^{1}$}

ISSUE DOI: $10.21207 / 1983.4225 .328$

\section{RESUMO}

O presente trabalho tem, como importante abordagem, as alterações ocorridas no Novo Código de Processo Civil, mais especificamente nos artigos 485 e 489 os quais abordaram a disciplina de sentença. No novo Código de Processo Civil acrescentaram-se determinações para que a fundamentação da sentença seja considerada apta a fazer coisa julgada, devendo o juiz enfrentar e justificar os motivos do seu convencimento. Sendo assim, busca-se responder se diante das modificações ocorridas e das exigências quanto à sentença, as mesmas não irão contra a celeridade processual que se busca no novo Código de Processo Civil.

Palavras-chave: Direito Processual Civil. Sentença. Citra petita. Celeridade.

\footnotetext{
${ }^{1}$ Graduada em Direito pelo Centro Universitário Franciscano, UNIFRA. Advogada na Dupuy Advogados.
} 


\section{ABSTRACT}

This work is important to approach the changes in the New Civil Procedure Code, specifically Articles 485 and 489 which addressed the sentence discipline. In the new Code of Civil Procedure were added determinations for the sentence of the reasons is deemed fit to do res judicata, and the judge should face and justify the reasons for his conviction. Therefore, we sought to answer was on the alterations and the requirements for the award, they will not against the promptness is sought in the new Civil Procedure Code.

Keywords: Sentences. Citra Petita. Celerity.

\section{INTRODUÇÃO}

O trabalho é desenvolvido na busca de responder questões que surgem com a reforma do Novo Código de Processo Civil, que, consequentemente, trará reflexos no andamento processual e na vida daqueles que buscam no judiciário a garantia de direitos que em algum momento foram violados.

A problemática do trabalho envolve as mudanças relevantes para o andamento processual, bem como, a busca da celeridade para que os litígios se "desenrolem" mais rápido.

O Código de Processo Civil teve, em seu corpo, algumas alterações relevantes, e apesar de ser esculpido com base na celeridade processual, há modificações que criam indagações quanto a isso.

Como as ocorridas nos artigos referentes à fundamentação da sentença, em especial o artigo 489, e, se, as mesmas fomentaram a invocação de vícios como sentenças citra petita quando não existirem, ou não causarem maiores problemas, tornando o processo ainda mais moroso, entrando assim em conflito com a ideia central de celeridade processual do novo Código de Processo Civil.

Cabe perquirir sobre a possibilidade de nulidade ou integração das sentenças que não abordarem todas as questões relevantes no processo, sentenças conhecidas como citra petita, causando uma dilação no andamento processual. 


\section{DAS SENTENÇAS E SEUS VícIOS}

A sentença também conhecida como decisão judicial, é o momento do processo em que o juiz encerra a fase cognitiva do processo, ou seja, quando o juiz reconhece ou não a existência de um direito lesado.

Os atos do juiz devem encontrar-se diretamente ligados para que ele possa resolver as demandas que lhe foram destinadas, devendo assim guardar relação com as pretensões do autor e com os atos praticados pelo juiz, bem como, as decisões tomadas.

Essas decisões proferidas pelo juiz encontram limites nos pedidos requeridos pelas partes: o legislador em seu artigo 141 do Novo Código de Processo Civil, advento da Lei 13.105/15 que manteve sentido idêntico ao artigo 128 do Código de 1973, vedou o juiz de conhecer questões não suscitadas e questões que dependem da iniciativa das partes. Quanto a isso, explanam Junior e Nery, em seu livro sobre comentários ao Código de Processo Civil:

Deve haver correlação entre pedido e sentença, sendo defeso ao juiz decidir aquém (citra ou infra petita), fora (extra petita) ou além (ultra petita) do que foi pedido, se para isto a lei exigir a iniciativa das partes. Caso decida com algum dos vícios apontados, a sentença poderá ser corrigida com embargos de declaração, se citra ou infra petita, ou por recurso de apelação, se tiver sido proferida extra ou ultra petita. Por pedido deve ser entendido o conjunto formado pela causa (ou causae) petendi e o pedido em sentido estrito. A decisão do juiz fica vinculada à causa de pedir e ao pedido. ${ }^{2}$

O novo Código de Processo Civil, em seu artigo 492 expõe que "é vedado ao juiz proferir decisão de natureza diversa da pedida, bem como, condenar a parte em quantidade superior ou em objeto diverso do que lhe foi demandado", complementado pelo artigo 141 do mesmo Código.

\footnotetext{
2 NERY JUNIOR, Nelson. NERY, Rosa Maria de Andrade. Comentários ao Código de Processo Civil - Novo CPC - Lei 13.105/2015. $12^{\circ}$ Ed. São Paulo: Revista dos Tribunais, 2012. p. 590.
} 
Os dispositivos legais citados são os alicerces para a regra de congruência da decisão judicial, que teve origem no Direito Romano e sustenta o que anteriormente foi descrito: o juiz é sujeito inerte na relação processual, devendo responder aquilo que foi requerido pelas partes.

A regra de congruência, busca ainda como fundamento o direito ao contraditório, estabelecendo limitação ao exercício de jurisdição, devendo o juiz julgar com base nos fundamentos dos fatos da demanda e da defesa e os pedidos formulados.

Reforçando a regra de que o juiz age mediante provocação, assim, segundo o código, o juiz deve decidir as demandas dentro daquilo que foi suscitado pelas partes, não podendo exceder no seu julgamento, bem como, julgar diverso do requerido, ou ainda, deixando de julgar algum dos pedidos.

Quando o juiz decide além do que foi suscitado pelas partes, está-se diante de uma sentença ultra petita; se julga fora dos pedidos suscitados, é extra petita; já se ficar aquém ou deixar de se pronunciar sobre algum dos pedidos, será uma sentença citra petita, todos considerados vícios da sentença.

A sentença ultra petita julga fatos e pedidos não discutidos ou requeridos no processo, o qual ofende o princípio do contraditório e do devido processo legal.

Quanto à sentença extra petita, o magistrado deixa de analisar o que deveria e analisa outra coisa em seu lugar.

A sentença citra petita é a que será analisada com mais afinco nesse trabalho, e, segundo doutrinadores, violaria o princípio da inafastabilidade do controle jurisdicional. Tal sentença se configura por ausência de manifestação sobre os pedidos ou algum pedido, sobre os fundamentos de fato ou de direito exarados pelas partes, sendo uma sentença omissa, pois o magistrado se oculta de analisar algo.

Entretanto, há dois tipos de decisões omissas, quais sejam: aquela que não examinou o pedido da questão principal, e, aquela que não examinou algum fundamento que poderia influenciar na decisão.

As decisões judiciais em que o juiz desconsidera parte do pedido ou um dos pedidos integrantes da pretensão podem ocorrer na cumulação de pedidos, sendo um pedido uno, mas que formalmente se desdobra em tantos pedidos quantos a causa de pedir. E a cumulação simples de pedidos em que cada pedido deve ser acolhido ou rejeitado na sentença, 
independente do outro, ambos os casos são exemplos de sentenças citra petita.

Contudo, quando a sentença for omissa em algum ponto, há doutrinadores como Nery e Junior anteriormente citados, que entendem que o vício pode ser sanado com embargos de declaração ou em sede de recurso de apelação, mas se tal omissão for sobre ponto fundamental da demanda, seria o caso de nulidade da sentença, causando uma divergência na maneira de sanar o vício.

\section{ALTERAÇÕES DO NOVO CÓDIGO DE PROCESSO CIVIL NAS SENTENÇAS}

O novo Código de Processo Civil trouxe significativas mudanças em matéria de sentenças, abordadas no Código de Processo Civil de 1973 no artigo 267 os casos em que o processo era extinto sem resolver o mérito, no novo Código desponta no artigo 485, conforme se verifica:

Art. 485. O juiz não resolverá o mérito quando:

I - indeferir a petição inicial;

II - o processo ficar parado durante mais de 1 (um) ano por negligência das partes;

III - por não promover os atos e as diligências que lhe incumbir, o autor abandonar a causa por mais de 30 (trinta) dias;

IV - verificar a ausência de pressupostos de constituição e de desenvolvimento válido e regular do processo;

V - reconhecer a existência de perempção, de litispendência ou de coisa julgada;

VI - verificar ausência de legitimidade ou de interesse processual;

VII - acolher a alegação de existência de convenção de arbitragem ou quando o juízo arbitral reconhecer sua competência;

VIII - homologar a desistência da ação;

IX - em caso de morte da parte, a ação for considerada intransmissível por disposição legal; e $\mathrm{X}$ - nos demais casos prescritos neste Código. 
$\S$ 1o Nas hipóteses descritas nos incisos II e III, a parte será intimada pessoalmente para suprir a falta no prazo de 5 (cinco) dias.

$\S 20$ No caso do $\S 10$, quanto ao inciso II, as partes pagarão proporcionalmente as custas, e, quanto ao inciso III, o autor será condenado ao pagamento das despesas e dos honorários de advogado.

§ 3o O juiz conhecerá de ofício da matéria constante dos incisos IV, V, VI e IX, em qualquer tempo e grau de jurisdição, enquanto não ocorrer o trânsito em julgado.

§ 4o Oferecida a contestação, o autor não poderá, sem o consentimento do réu, desistir da ação.

§ 5o A desistência da ação pode ser apresentada até a sentença.

§ 6o Oferecida a contestação, a extinção do processo por abandono da causa pelo autor depende de requerimento do réu.

$\S 7$ o Interposta a apelação em qualquer dos casos de que tratam os incisos deste artigo, o juiz terá 5 (cinco) dias para retratar-se.

Conforme se verifica em comparação ao Código de Processo Civil de 1973 , foram acrescentados os $\S \S \S 5^{\circ}, 6^{\circ}$ e $7^{\circ}$, que mencionam os casos de desistência da ação, bem como, a retratação do juiz nos casos de processo extinto por algum dos incisos do referido artigo.

Contudo, no artigo 487 do novo Código, que anteriormente encontrava-se no artigo 269, estão elencadas as hipóteses que resolvem o mérito, a seguir:

Art. 487. Haverá resolução de mérito quando o juiz: I - acolher ou rejeitar o pedido formulado na ação ou na reconvenção;

II - decidir, de ofício ou a requerimento, sobre a ocorrência de decadência ou prescrição;

III - homologar:

a) o reconhecimento da procedência do pedido formulado na ação ou na reconvenção;

b) a transação;

c) a renúncia à pretensão formulada na ação ou na reconvenção. 
Parágrafo único. Ressalvada a hipótese do $\S 1^{\circ}$ do art. 332, a prescrição e a decadência não serão reconhecidas sem que antes seja dada às partes oportunidade de manifestar-se.

Já no artigo 487, a importante mudança ocorrida foi o acréscimo do parágrafo único, o qual não permite o reconhecimento da prescrição e decadência sem a manifestação das partes antes de ser decretada, e no caso de o juiz acolher ou rejeitar o pedido formulado pelas partes, estará resolvendo o mérito da demanda, ou seja, estará proferindo uma sentença.

Cabe referir que a sentença ou também conhecida como decisão judicial, pode resolver a demanda como também extinguir o processo sem a resolução do mérito.

A lei 13.105/15 do Novo Código de Processo Civil que entrará em vigor dia 18 de março do presente ano, traz em seu artigo 489, sobre os elementos essenciais da sentença, quais sejam: o relatório, fundamentação e o dispositivo, apresentando um extenso rol de hipóteses em que a sentença não será considerada fundamentada, conforme se demonstra a seguir:

Art. 489. São elementos essenciais da sentença:

I - o relatório, que conterá os nomes das partes, a identificação do caso, com a suma do pedido e da contestação, e o registro das principais ocorrências havidas no andamento do processo;

II - os fundamentos, em que o juiz analisará as questões de fato e de direito;

III - o dispositivo, em que o juiz resolverá as questões principais que as partes lhe submeterem.

$\S 1^{\circ}$ Não se considera fundamentada qualquer decisão judicial, seja ela interlocutória, sentença ou acórdão, que:

I - se limitar à indicação, à reprodução ou à paráfrase de ato normativo, sem explicar sua relação com a causa ou a questão decidida;

II - empregar conceitos jurídicos indeterminados, sem explicar o motivo concreto de sua incidência no caso;

III - invocar motivos que se prestariam a justificar qualquer outra decisão; 
IV - não enfrentar todos os argumentos deduzidos no processo capazes de, em tese, infirmar a conclusão adotada pelo julgador;

$\mathrm{V}$ - se limitar a invocar precedente ou enunciado de súmula, sem identificar seus fundamentos determinantes nem demonstrar que o caso sob julgamento se ajusta àqueles fundamentos; VI - deixar de seguir enunciado de súmula, jurisprudência ou precedente invocado pela parte, sem demonstrar a existência de distinção no caso em julgamento ou a superação do entendimento.

$\S 2^{\circ}$ No caso de colisão entre normas, o juiz deve justificar o objeto e os critérios gerais da ponderação efetuada, enunciando as razões que autorizam a interferência na norma afastada e as premissas fáticas que fundamentam a conclusão.

$\S 3^{\circ} \mathrm{A}$ decisão judicial deve ser interpretada a partir da conjugação de todos os seus elementos e em conformidade com o princípio da boa-fé.

Nesse artigo, incluem-se hipóteses de quando não se considerará fundamentada a decisão judicial; não estando presente algum deles torna $\mathrm{o}$ ato padecente de vício.

O relatório da sentença faz um breve resumo do que ocorreu no desenrolar do processo, constando as partes, a identificação do caso, os pedidos postulados; nele o juiz demonstra que examinou os atos essenciais, valorou as provas, fiscalizou a validade do processo, ou seja, que a demanda foi analisada na íntegra.

Na fundamentação da sentença, o juiz analisará as questões de fato e de direito, sendo de extrema relevância para a construção do raciocínio, argumentando desde já a posição que será tomada pelo juiz, ou seja, expondo sua motivação para a decisão. A falta da fundamentação, ou ainda, sua carência poderá causar a nulidade da decisão judicial, contudo Junior e Nery, (2015, p.1153) expõem o seguinte:

Quando a sentença acolher um dos fundamentos do pedido ou da defesa, bastante para determinar-se a procedência ou improcedência do pedido, pode ser que seja desnecessário que ingresse no exame das demais alegações. Esse temperamento é necessário e 
útil, pois há situações em que o juiz fundamenta pelo máximo, não fazendo sentido examinar as alegações de menor importância ${ }^{3}$.

Nesse deslinde, segundo os autores referidos não se faz necessária em alguns casos a fundamentação de todos os fatos, contudo as alterações do Novo Código passaram a considerar as decisões fundamentadas somente quando a sentença examinar todos os argumentos colocados pelas partes.

Quanto ao dispositivo, é a parte da sentença que faz coisa julgada, concretizando o cerne volitivo da sentença, sendo o momento em que se dá uma resposta acerca da procedência ou da improcedência do pedido formulado pelo autor, necessitando serem analisados todos os pedidos requeridos, inclusive aquele demandado em reconvenção pelo réu e os pedidos implícitos.

No entanto, para haver uma sentença citra petita necessariamente deverá haver uma cumulação de pedidos, pois havendo somente um e o juiz não analisar esse pedido, não haverá uma decisão.

A cumulação de pedidos é dividida em simples, sucessiva, subsidiária e a cumulação alternativa. A cumulação simples trata de pedidos independentes, que obriga o juiz a se manifestar sobre o todo. A sucessiva depende da análise do primeiro pedido para a procedência do ulterior.

Já para os pedidos subsidiários, há uma ordem de preferência, a procedência do primeiro impossibilita a apreciação dos demais. Por fim, a cumulação alternativa, a procedência de qualquer um dos pedidos realizados prescreve os demais, não sendo necessário o enfrentamento dos demais pedidos.

O inciso IV do artigo 489, referente ao Novo Código de Processo Civil, delimita que se não enfrentados todos os argumentos deduzidos no processo, a decisão judicial não será considerada fundamentada, e a mera indicação de um dispositivo ou súmula poder ser insuficiente para argumentar a decisão proferida.

Essas significativas alterações ocorridas no novo Código de Processo Civil, fazem perquirir sobre a celeridade processual, visto que

\footnotetext{
${ }^{3}$ NERY JUNIOR, Nelson. NERY, Rosa Maria de Andrade. Comentários ao Código de Processo Civil - Novo CPC - Lei 13.105/2015. $12^{\circ}$ Ed. São Paulo: Revista dos Tribunais, 2012. p. 1153.
} 
surgirá a possibilidade de invocar vícios, como a sentença citra petita requerendo a nulidade das sentenças.

Eis que cabe elucidar: tais "brechas", que a lei proporcionou das alegações de vício, deverão ser analisadas com cuidado, já que o "vício" ocasionado por uma sentença citra petita, poderá ou não causar prejuízos para uma das partes no processo. Podendo ser simplesmente sanados com a propositura de embargos declaratórios ou em sede de recurso pelo Tribunal, o que será analisado no próximo capítulo.

\section{AS IMPLICAÇÕES DAS ALTERAÇÕES NO ANDAMENTO PROCESSUAL}

Para saber se se está diante de uma sentença, cabe averiguar seus efeitos no andamento processual; se colocar fim em umas das fases do processo, estar-se-á diante de uma sentença, na qual o juiz deve acolher ou rejeitar no todo ou em parte, o pedido formulado pelo autor.

Ocorre que, o Novo Código de Processo Civil ao colocar " $n$ " requisitos para considerar uma sentença fundamentada, abre precedentes para a invocação de vícios, como a sentença Citra Petita pela omissão no pronunciamento de algum dos pedidos, e assim atuando contra a celeridade processual, visto que, deve ser considerado na sentença citra petita o prejuízo para as partes na finalidade do processo.

O artigo 489 do Novo Código de Processo Civil teve relevantes acréscimos, elucidando os elementos essenciais das sentenças e sobrepondo possibilidades de considerar a decisão não fundamentada se a sentença não possuir os requisitos elencados nesse artigo.

Quando a sentença apresentar um vício no seu dispositivo, podendo ser a sentença citra petita, qual seja, a omissão em algum ponto da decisão judicial, a doutrina e a jurisprudência têm diferentes entendimentos.

Conforme se verifica em julgado do Tribunal de Justiça do Rio Grande do Sul, a saber:

Ementa: APELAÇÃO CÍVEL. ALIENAÇÃO FIDUCIÁRIA. AÇÃ̃O DE CONSIGNAÇÃO EM PAGAMENTO C/C PEDIDO DE REVISÃO CONTRATUAL. SENTENÇA CITRAPETITA. 
NULIDADE INSANÁVEL. Deve haver correlação entre o pedido e a sentença, não podendo o juiz decidir aquém (citra ou infra petita), fora (extra petita) ou além (ultra petita) do que foi postulado pelo autor, nos termos do art. 460 do CPC. No caso em comento, a sentença mostrou-se aquém dos pedidos veiculados na vestibular, deixando de apreciar os pleitos relativos à nulidade da nota promissória e da cláusula-mandato. Dessa feita, a desconstituição do julgado é medida que se impõe, porquanto a prestação jurisdicional não foi esgotada, não podendo esta Corte se manifestar agora, em grau de recurso, sobre matéria não apreciada na origem, por implicar supressão de instância, o que representa afronta ao princípio do duplo grau de jurisdição. SENTENÇA DESCONSTITUÍDA, DE OFÍCIO. APELO PREJUDICADO. UNÂNIME. (Apelação Cível No 70052460169, Décima Quarta Câmara Cível, Tribunal de Justiça do RS, Relator: Elaine Maria Canto da Fonseca, Julgado em $03 / 03 / 2016)^{4}$.

No que tange a sentença Citra Petita, conforme decisão do tribunal anteriormente colecionada, a sentença será nula, mas para alguns doutrinadores poderia ser suprida pelo Tribunal em sede de recurso, ou ainda, ser sanada com embargos declaratórios.

Conforme ensinam os doutrinadores Nery JR. e Rosa Maria Nery, in Comentários ao Código de Processo Civil, a saber:

Correlação entre pedido, causa de pedir e sentença. $\mathrm{O}$ autor fixa os limites da lide e da causa de pedir na petição inicial (CPC 128), cabendo ao juiz decidir de acordo com esse limite. É vedado ao magistrado proferir sentença acima (ultra), fora (extra) ou abaixo (citra ou infra) do pedido. Caso o faça, a sentença estará eivada de vício, corrigível por meio de recurso. A sentença citra ou infra petita pode ser

\footnotetext{
${ }^{4}$ BRASIL, Tribunal de Justiça do Rio Grande do Sul; Sentença Citra Petita e Nulidade Insanável, julgado em 03 de março de 2016. Disponível em: http://www.tjrs.jus.br. Acesso em: 07 de mar. de 2016.
} 
corrigida por meio de embargos de declaração, cabendo ao juiz suprir a omissão; a sentença ultra ou extra petita não pode ser corrigida por embargos de declaração, mas só por apelação. Cumpre ao Tribunal, ao julgar o recurso, reduzi-la aos limites do pedido. $^{5}$

Diante disso, deve se analisar se essa não fundamentação na sentença, alvo de insurgência no recurso de apelação, deve ser anulada ou pode ser suprida por julgamento perante o Tribunal.

Cabe ressalvar, que o recurso de apelação possui o efeito devolutivo, restituindo ao tribunal a matéria impugnada pelas partes, ou seja, o tribunal deve se manifestar daquilo que as partes aduziram em razões ou contrarrazões do recurso, limitando o tribunal no caso de o autor pedir somente a anulação da sentença citra petita.

Deve o juiz conferir ao processo efetividade, celeridade e eficiência, cabendo ao juiz fundamentar a decisão, porém se possuir o vício enquanto não decretado o ato produz os seus efeitos.

Quanto à invalidação da decisão omissa por apresentar vício, expõem Didier, Braga e Oliveira ${ }^{6}$ :

Não há vício naquilo que não existe. Só tem defeito aquilo que foi feito. Se um pedido não foi examinado, não houve decisão em relação a esse pedido e, portanto, não se pode falar em vício. Do mesmo modo, a solução dos demais pedidos, efetivamente resolvidos, não fica comprometida ou viciada pelo fato de um dos pedidos não ter sido examinado. Nesses casos, a decisão precisa ser integrada e não invalidada; não se pode invalidar o que não existe. A integração da decisão é uma das possíveis pretensões que podem ser deduzidas em um recurso. Integrar a decisão é torná-la inteira,

\footnotetext{
${ }^{5}$ NERY JUNIOR, Nelson. NERY, Rosa Maria de Andrade. Comentários ao Código de Processo Civil - Novo CPC - Lei 13.105/2015. 12 Ed. São Paulo: Revista dos Tribunais, 2012. p. 1205.

${ }^{6}$ DIDIER JR., Freddie. BRAGA, P.S. OLIVEIRA, R.A. Curso de Direito Processual Civil: teoria da prova, direito probatório, ações probatórias, decisão, precedente, coisa julgada e antecipação dos efeitos da tutela. $10^{\circ}$ Ed. Bahia: JusPodium, 2015. p. 255.
} 
completa, perfeita; integrar a decisão não é invalidála.

Dessa forma, desde que o processo que deu origem à sentença citra petita, tenha respeitado o devido processo legal e os princípios basilares da nossa Carta Magna, como o contraditório e a ampla defesa, não há justificativa para sua anulação.

Conforme os autores Didier, Braga e Oliveira, em seu livro, garantem que a sentença omissa não apresenta vício, podendo ser "integrada" pelo tribunal, ou seja, ser complementada quanto à parte não analisada, ou não pronunciada pelo Juiz, não sendo passível de invalidação.

$\mathrm{Na}$ busca de oferecer a tutela jurisdicional de maneira mais célere deve o tribunal se manifestar sobre os pedidos não apreciados pelo juízo a quo. O autor Dinamarco partilha do mesmo entendimento, a saber:

Também em apelação contra sentença de mérito omissa quanto a um dos pedidos postos no processo (pedido cumulado, reconvenção etc.) cumprirá ao tribunal decidir a respeito, sempre que a causa esteja madura para julgamento do pedido negligenciado. Não será o caso de devolver os autos para que o faça o juiz inferior e, muito menos, de anular o que foi julgado por conta do que não o foi. O julgamento pelo tribunal, em hipóteses assim, constitui desdobramento rigorosamente legítimo do disposto no $\S 3^{\circ}$ do art. 515 do Código de Processo Civil e de seu espírito agilizador, sendo fortíssima a analogia entre sentença terminativa, cuja a reforma pode induzir ao julgamento do mérito, e a sentença de mérito que deveria conter um capítulo a mais, mas que por devida omissão não o contém. Em ambos os casos teremos um julgamento de mérito pelo tribunal, sem que o mérito houvesse sido julgado pelo juiz inferior (mérito da causa com um todo na primeira hipótese e mérito de um dos pedidos, na segunda delas). ${ }^{7}$

7 DINAMARCO, Cândido Rangel. Nova era do processo civil. Imprenta: São Paulo, Malheiros, 2007. p. 183-184. 
Nesse sentido, Junior e Nery em seu livro anteriormente citado, expõem:

Quando a causa encontra-se no tribunal de segunda instância, em grau de recurso, torna-se imperativo que o juiz ad quem examine todos os fundamentos expostos nas razões e contrarrazões (efeito devolutivo - CPC $1013 \S 2 .^{\circ}$ ), bem como as questões de ordem pública (efeito translativo - CPC 485 §3..$^{\circ}$ ), observando quanto a este último, o disposto no CPC 10 para que seja respeitado o contraditório e se evite decisão surpresa. Pelo efeito devolutivo da apelação, o exame de todas as questões suscitadas e discutidas no processo, ainda que não analisadas por inteiro pelo juízo de primeiro grau, fica devolvida ao tribunal que sobre elas deve obrigatoriamente se pronunciar. ${ }^{8}$

Percebe-se que os autores seguem uma tese de defesa semelhante, ou seja, se o juízo a quo não se manifestou em sua decisão de todos os pedidos realizados pelas partes no decorrer do processo, ou seja, havendo uma omissão quanto algum pedido, as partes podem recorrer da decisão, e assim o tribunal se manifestará sobre o todo, completando a decisão, e não declarando sua nulidade.

Se reconhecida a nulidade da sentença em recurso de apelação, o maior prejuízo seria para as partes, pois haveria o retardamento da solução do litígio, retornando ao juízo a quo para suprir a omissão, sendo esse o entendimento do Tribunal do Rio Grande do Sul.

Neste liame, percebe-se que mesmo diante de um rol extenso de hipóteses para não considerar a decisão do juiz fundamentada, a omissão diante de algum dos pedidos das partes não seria motivo para nulidade da sentença; segundo entendimento doutrinário, é caso de integração da sentença, sendo cabível pelo próprio tribunal em sede de recurso.

\footnotetext{
${ }^{8}$ NERY JUNIOR, Nelson. NERY, Rosa Maria de Andrade. Comentários ao Código de Processo Civil - novo CPC - Lei 13.105/2015. São Paulo: Revista dos Tribunais, 2015. p. 1153.
} 


\section{CONSIDERAÇÕES FINAIS}

O princípio da congruência dos pedidos é um limitador do direito de jurisdicionar do juiz, devendo haver uma conexão entre os pedidos das partes e a fundamentação do juiz. Sendo o juiz ao julgar omisso em alguns dos pedidos das partes, a sentença apresentará um vício, qual seja, a sentença citra petita.

A sentença quando apresentada citra petita possibilita a insurgência de sua nulidade, contudo como explanado, quando nulas irão contra a celeridade processual que se buscou nesse novo Código de Processo Civil.

O ato jurídico nulo é aquele que traz prejuízo a uma das partes; a sentença quando omissa em algum ponto pode ser objeto de recurso no qual o Juízo ad quem deverá proceder à complementação da sentença sobre determinado ponto.

Sendo o processo calcado nos princípios fundamentais para a sua resolução, deverá o tribunal julgá-lo, sanando o vício sem gerar a sua nulidade, buscando a preservação dos atos processuais, visto que, conforme se conclui com o presente trabalho a sentença citra petita não geraria uma nulidade, sendo sanável o vício com a integração da sentença pelo juízo ad quem.

Contudo, o novo Código de Processo Civil apesar de ser elaborado na busca da celeridade para os conflitos, ao acrescentar requisitos para a validade da sentença, abriu precedentes de invocação de nulidade de sentença.

\section{REFERÊNCIA BIBLIOGRÁFICA}

BRASIL, Tribunal de Justiça do Rio Grande do Sul; Sentença citra petita e nulidade insanável, julgado em 03 de março de 2016. Disponível em: http://www.tjrs.jus.br. Acesso em: 07 de mar. de 2016.

Código de processo civil. Disponível em: http://www.planalto.gov.br. Acesso em 25 de fev. de 2016. DIDIER JR., Freddie Braga, P.S. OLIVEIRA, R.A. Curso de direito processual civil: direito probatório, decisão judicial, 
cumprimento e liquidação da sentença e coisa julgada. Salvador: JusPodium, 2007.

- Curso de direito processual civil: teoria da prova, direito probatório, ações probatórias, decisão, precedente, coisa julgada e antecipação dos efeitos da tutela. $10^{\circ} \mathrm{Ed}$. Bahia: JusPodium, 2015.

DINAMARCO, Cândido Rangel. Nova era do processo civil. $2^{\circ}$ Ed. São Paulo: Malheiros, 2007.

NERY JUNIOR, Nelson. NERY, Rosa Maria de Andrade. A. Código de Processo Civil Comentado. $12^{\circ}$ Ed. São Paulo: Revista dos Tribunais, 2012.

. Comentários ao Código de Processo Civil - Novo CPC - Lei 13.105/2015. São Paulo: Revista dos Tribunais, 2015. 